\title{
MODELING OF DAM RESERVOIR VOLUME USING GENERALIZED REGRESSION NEURAL NETWORK, SUPPORT VECTOR MACHINES AND M5 DECISION TREE MODELS
}

\author{
ÜNEŞ, F. ${ }^{*}$ - DEMIRCI, M. - TAŞAR, B. - KAYA, Y.Z. - VARÇIN, H. \\ Hydraulics Division, Civil Engineering Department, Iskenderun Technical University \\ 31040 Iskenderun, Hatay, Turkey \\ *Corresponding author \\ e-mail: fatih.unes@iste.edu.tr; phone: +90-326-613-5600(2806) \\ (Received 22 ${ }^{\text {nd }}$ Feb 2019; accepted 29 $9^{\text {th }}$ Mar 2019)
}

\begin{abstract}
Dam reservoir capacity estimation is an important issue for operation, design and safety assessments of dam structures. In this study, the reservoir capacity of the Stony Brook dam in the USA was estimated by Generalized Regression Neural Network (GRNN), Support Vector Machines (SVM) and M5 Tree Model (M5T) methods with using 3726 data taken from United States Geological Survey Institute (USGS) for 2012-2015 years. Listed soft computing techniques give opportunities to researchers working on non-linear problems. Based on the non-linear approach, models are generated by using precipitation, flow, temperature hydrological parameters. The models were compared with each other according to the three statistical criteria, namely, mean absolute error (MAE), root mean square error (RMSE), and determination coefficient. As a result of the study, it is seen that Support Vector Machines (SVM) models have better performance in predicting dam reservoir level than the other used soft computing models.
\end{abstract}

Keywords: estimation, reservoir management, soft computing techniques, neural network, statistical approach

\section{Introduction}

Control of the water volume in the reservoir is achieved by accumulating and distributing water at the right time. There may be loss of life and property due to nontimely measures and water-related problems such as flood planning and management, design and operation of the hydraulic structures, navigation in the dam reservoirs, water supply for municipalities and industries, irrigation and drainage, flood damage reduction and water quantity modeling in the reservoir. That is why a proper dam reservoir management is a requirement not only in terms of fresh water supply, but also to prevent potential damages. One of the basic requirements for managing the dam reservoir in the most effective way is to determine the reservoir water volume, estimations the elevations and outflows in this volume. There are so many direct or indirect effects on reservoir levels changes. These effects can be listed as influences of atmospheric, natural, social and environmental conditions. Subdivisions of listed effects are seasonal climate changes and global warming, topography of watershed, fresh water demand, water distribution etc. Each of these effects has different impact on reservoir volume fluctuations and it needs to be considered for analyzes.

Artificial Intelligence methods are called black box models and in recent years they are frequently used in hydraulic and water structures planning because of the prediction abilities of these methods on non-linear problems (Demirci and Baltac1, 2013; Demirci et al., 2015a, 2015b, 2019; Kaya et al., 2018; Tasar et al., 2017, 2018). Artificial Neural Networks (ANN) is one of these models. Artificial Neural Networks are able to solve 
complex problems successfully due to their ability to learn and generalize (Ergezer et al., 2003). The foundations of the first modeling of artificial neural networks were laid in an article by McCulloch and Pitts (1943). They modeled simple artificial nerves on electrical circuits. Nowadays, there are many studies on the application of ANN to various cases frequently experienced in water resources. The ANN approach has been shown to represent the precipitation-flow relationship well (Mason et al., 1996; Minns and Hall, 1996; Fernando and Jayawardena, 1998). Turhan (2012) modeled the precipitation-flow relationship of the Seyhan Basin with the ANN method. Unes (2010a) predicted dam reservoir level by artificial neural network. Unes (2010b) also predicted density flow plunging depth in dam reservoir using artificial neural network. Chitsaz et al. (2016) used different estimation techniques for river flow forecasting and compared the results of generalized regression neural network (GRNN), multi-layer perceptron (MLP), adaptive neuro-fuzzy inference system (ANFIS) with each other. The result illustrated that MLP outperformed ANFIS and GRNN. Demirci et al. (2018) predicted dam reservoir volume using adaptive neuro-fuzzy inference system (ANFIS). Yin et al. (2016) compared abilities of different GRNN models such as rotated general regression neural network (RGRNN), feed-forward error back-propagation (FFBP) for river flow forecasting, models are created for semi arid region in China and results clarify that the combined RGRNN model has better performance on river flow forecasting. Unes et al. (2017) predicted dam reservoir volume using adaptive neuro fuzzy approach (ANFIS).

Support Vector Machines (SVM) are machine learning algorithms developed by Vapnik and other researchers (Vapnik, 1995; Cortes and Vapnik, 1995; Vapnik et al., 1997). This approach was originally developed as a way of interpreting sensor data and includes a two-tier structure. The first layer is a weightless nonlinear nucleus on the support vectors containing the input variable series, and the second is a weighted sum of core outputs. Once support vectors and appropriate core filters have been applied, the performance of SVM can be much better than the one of the other soft computing technique ANN in many cases. Many studies have been done for the learning of possible solving performance of SVM in hydrological problems. Dibike et al. (2001) investigated SVM performance for rainfall-runoff modeling and compared to ANN models. Bray and Han (2004) underlined the difficulty in determining a suitable model structure and related parameters for precipitation modeling. Chen et al. (2010) used SVMs to predict daily rainfall in the Hanjiang basin. The SVM technique has recently been effective in solving forestry problems (Nieto et al., 2012), in determining solar rays (Antonanzas et al., 2015) and predicting daily rainfall-runoff (Hosseini and Mahjouri, 2016). Recently, SVMs have been widely used to predict rainfall-runoff and water reservoirs. (flood and stream flow (Yu et al, 2006), atmospheric temperature (Radhika and Shashi, 2009), lake water levels (Khan and Coulibaly, 2006; Asefa et al., 2005; Khalil et al., 2006). Unes al. (2013) estimated dam reservoir level using artificial neural (ANN) network and support vector machines (SVM). M5T is one of the algorithms of decision trees. Decision trees, classification and regression can be applied to problems, effective, non-parametric, is a method that requires intensive calculation (Rao et al, 2007) The application of decision trees in hydrology is limited; only a part of published articles were used to estimate the dam reservoir capacity. Bhattacharya and Solomatine (2005) and Solomatine and Xue (2004) proved that M5T was very effective technique in the prediction rainfall-runoff. Goyal et al. (2013) applicated ANN, fuzzy logic and decision tree models (M5T) for the development of reservoir operating rules. 
Sattari et al. (2013) used M5T for Turkey, Ankara, Sohi River to investigate the potential of daily stream flow. Esmaeilzadeh et al. (2017) studied performance evaluation of ANNs and an M5T model tree in Sattarkhan Reservoir inflow prediction.

Aim of this study is to estimate the reservoir capacity of the Stony Brook dam in Massachusetts, USA. By using temperature, precipitation and flow data, the reservoir capacity was estimated with GRNN, SVM and M5T models and the models were compared with each other.

\section{Materials and methods}

\section{Study area}

In this study, dam reservoir volume was estimated by using the temperature, precipitation and flow data obtained from the United States Geological Survey (USGS). The Stony Brook dam reservoir in the USA was selected as application area (Fig. 1). (USGS station no: 01104480). The Stony Brook dam is located in Middlesex County, Massachusetts with $42^{\circ} 35^{\prime} 46.3^{\prime \prime}\left(42.5962^{\circ}\right)$ latitude and $71^{\circ} 26^{\prime} 18.7^{\prime \prime}\left(71.4385^{\circ}\right)$ longitude. Drainage area of dam reservoir is $70.7 \mathrm{~km}^{2}$. Stony Brook Reservoir reaches a height of $21 \mathrm{~m}$; the deepest point is about $9.15 \mathrm{~m}$, roughly $1.608 .10^{6} \mathrm{~m}^{3}$ of water at full capacity. Stony Brook is relatively small compared to the large basin and is much faster than other dams. Ekstrem air-temperatures were recorded as maximum, $36.5^{\circ} \mathrm{C}$, and minimum, $-23.3{ }^{\circ} \mathrm{C}$ for all the dam catchment area. Stony Brook dam catchment's climate is classified as warm and temperate. Stony brook catchment has a significant amount of rainfall during the year. The average annual temperature is $11.3{ }^{\circ} \mathrm{C}$ in Stony brook. About $1025 \mathrm{~mm}$ of precipitation falls annually. 3726 daily data for five years were used between 2012-2017 years.

Daily air average temperature, precipitation, river inflow, lag time reservoir volume are taken as inputs and reservoir volume as output of the models. The temperature, precipitation, flow and past reservoir volume (time, $\mathrm{t}-1$ ) of the Stony Brook dam were taken as input. 2126 of 3726 data were used for the training; remaining 1600 data were utilized for the test. Probable volumes in the next times are generated by the Generalized Regression Neural Network (GRNN), Support Vector Machines (SVM) and M5 Tree Model (M5T) artificial techniques. Reliability of the model results are examined with error parameters as root mean square error, mean absolute error, and coefficient of determination $\left(\mathrm{R}^{2}\right)$ between model volume estimations and observed reservoir volumes.

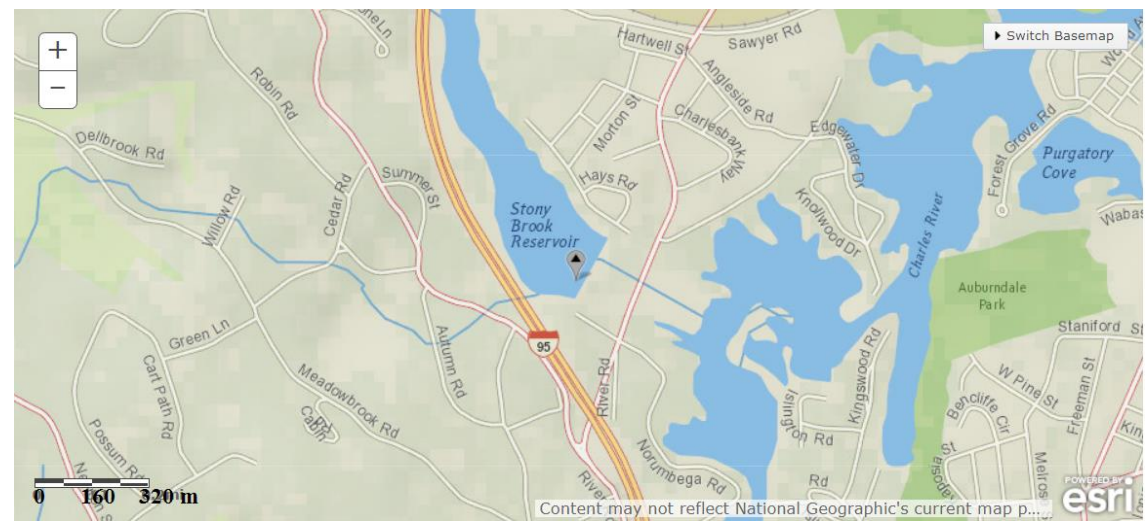

Figure 1. Overview of Stony Brook Dam (USGS) 


\section{Methods}

In this study 3726 day precipitation, flow and temperature data of the observation station were used in the Stony Brook Reservoir volume prediction. The results of Generalized Neural Network (GRNN), Support Vector Machines (SVM) and M5 Tree Model (M5T) are given as follows. The root mean square error (RMSE), mean absolute error (MAE), and the determination coefficients $\left(\mathrm{R}^{2}\right)$ were calculated for each model. The results were also used to compare the performance of the model estimation and observation data. RMSE and MAE are determined as follows in Equations 1 and 2, respectively:

$$
\begin{gathered}
\text { RMSE }=\sqrt{\frac{1}{\mathrm{~N}} \sum_{\mathrm{i}=1}^{\mathrm{N}}\left(\mathrm{Y}_{\mathrm{i}_{\text {observed }}}-\mathrm{Y}_{\mathrm{i} \text { prediction }}\right)^{2}} \\
\text { MAE }=\frac{1}{\mathrm{~N}} \sum_{\mathrm{i}=1}^{\mathrm{N}}\left|\mathrm{Y}_{\mathrm{i}_{\text {observed }}}-\mathrm{Y}_{\mathrm{i} \text { prediction }}\right|
\end{gathered}
$$

where $\mathrm{N}$ is the data number and $\mathrm{Yi}$ is the reservoir volume data. Determination coefficient $\left(\mathrm{R}^{2}\right)$, root mean square error (RMSE) and absolute mean error (MAE) were calculated for the performance evaluation of GRNN, SVM and M5T models.

\section{Support vector machines (SVM)}

Support vector (SVM) is machine-learning approach in data-driven research fields which founded by Cortes and Vapnik (1995). SVM is basically used to best distinguish between two data classes. For this purpose decision limits or hyper planes are determined. In a non-linear dataset, SVM cannot draw a linear hyper plane. Therefore, the kernel numbers are used. The Kernel method greatly improves machine learning in nonlinear data. In the kernel method, the SVM estimator (y) process can be expressed as in Equation 3:

$$
\mathrm{y}=\left(\mathrm{K}_{\mathrm{xi}} \cdot \mathrm{W}_{\mathrm{jk}}\right)+\mathrm{b}
$$

In Equation 3, b is the bias term of the SVM network, and $\mathrm{W}_{\mathrm{jk}}$ is called the weight vector. $\mathrm{K}_{\mathrm{xi}}$ is a non-linear function that maps input vectors to a high-dimensional property field. The structure of the SVM model with three layers used in this study is given in Figure 2. The output value for this example SVM model is equal to the sum of the three products in the inputs and the independent combinations of Lagrange multipliers. Nonlinear nuclear functions used in this study are radial based kernel function and poly kernel functions.

\section{Support vector machines with radial base functions (SVM-RBF)}

Lagrange multipliers show the importance of training data sets for output data. The non-linear radial-based kernel function (Hsu et al., 2003) is shown in the Equation 4:

$$
\mathrm{K}_{\mathrm{Xi}}=\mathrm{e}^{-\gamma\left\|\mathrm{p}_{\mathrm{i}}-\mathrm{y}_{\mathrm{i}}\right\|^{2}} \quad \gamma>0 \text { and } \mathrm{i}=1,2,3, \ldots \mathrm{n}
$$




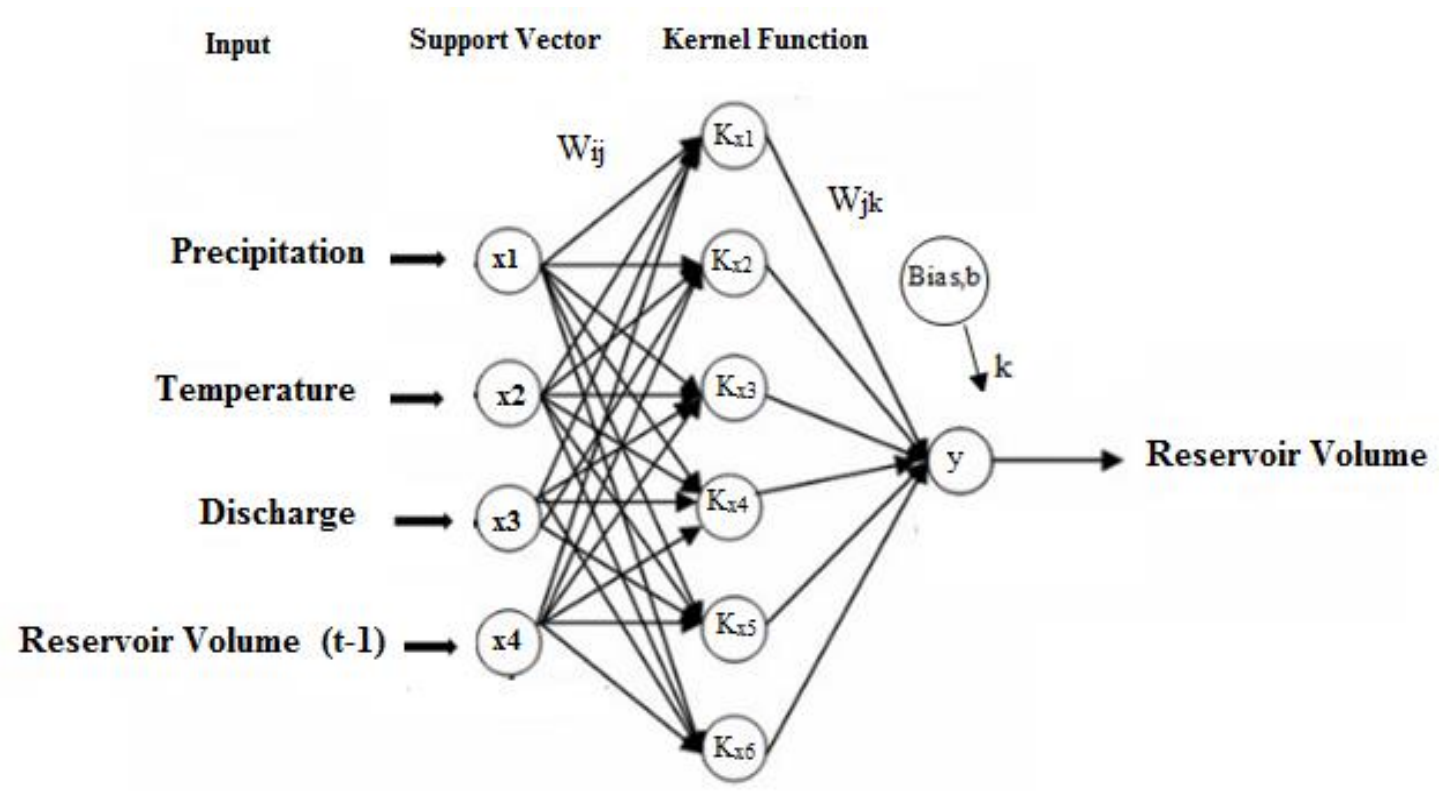

Figure 2. Structure of SVM-1 model used in this study

\section{Support vector machines with poly kernel (SVM-PK)}

Poly kernel function (Hsu et al, 2003) is shown by the Equation 5:

$$
\mathrm{K}_{\mathrm{Xi}}=(p \cdot y+c)^{d} \quad \mathrm{i}=1,2,3, \ldots \mathrm{n}
$$

\section{M5 decision tree method (M5T)}

A decision tree is a logical model shown as a binary (two-way split) tree that shows how the value of a dependent variable can be estimated by using the values of the argument set. There are basically two types of decision trees:

(1) Classification trees are the most common and a symbolic class used to estimate the value of a numerical attribute.

(2) Used to predict regression trees (Witten and Frank (2005).

If each leaf in the tree contains a linear regression model used to estimate the target variable in that leaf, then it is called a model tree.

The M5 decision tree algorithm was originally developed by Quinlan (1992). A detailed description of this technique can be found in Witten and Frank (2005). A brief description of this technique is as follows. The M5 algorithm creates a regression sequence by iteratively dividing the sample space using tests on a single attribute that maximizes the variance in the target space. Mathematical formula to calculate standard deviation reduction (SDR) can be written as in Equation 6:

$$
S D R=s d(T)-\sum I \frac{T i}{T} I s d I T i I
$$

where $\mathrm{T}$ represents a group of samples reaching the node; Ti represents a subset of samples that are the result of the potential cluster; and sd represents the standard deviation. After the tree is enlarged, a linear multiple regression is created for each 
internal node using all the attributes associated with that node and the tests in the subtest of that node. Each sub-tree is then taken into account in pruning to overcome the problem of pruning. Pruning occurs when the estimated error for the linear model at the root of a child tree is less than or equal to the expected error for the child tree. Finally, smoothing is used to compensate for sharp discontinuities between adjacent linear models in the leaves of the pruning tree.

\section{Generalized regression neural network (GRNN)}

The GRNN architecture (Specht, 1991) includes the radial basic function (RBF) method. Any optional function between input and output vectors is derived directly from training data. GRNN is based on nonlinear regression theory for function estimation. The training set consists of $\mathrm{x}$ input values, each of which has a corresponding value of y output. This regression method estimates the y value.

GRNN estimates any function between input and output vectors using the training data. As the training set expands, the prediction error is reduced to zero. GRNN is used for estimation of continuous variables, just like standard regression techniques. Figure 3 shows the Generalized Regression Neural Network model used in the present study.

Function classification with GRNN is done by using Equations 7 and 8:

$$
\begin{gathered}
\mathrm{K}\left(\mathrm{x}, \mathrm{x}_{\mathrm{k}}\right)=\mathrm{e}^{-\mathrm{d}_{\mathrm{K}} / 2 \sigma^{2}} \\
d_{K}=\left(x-x_{k}\right)^{T} *\left(x-x_{k}\right)
\end{gathered}
$$

where $d_{K}$ is the squared Euclidean distance between the training samples $x_{k}$ and the input $x$

Input Layer

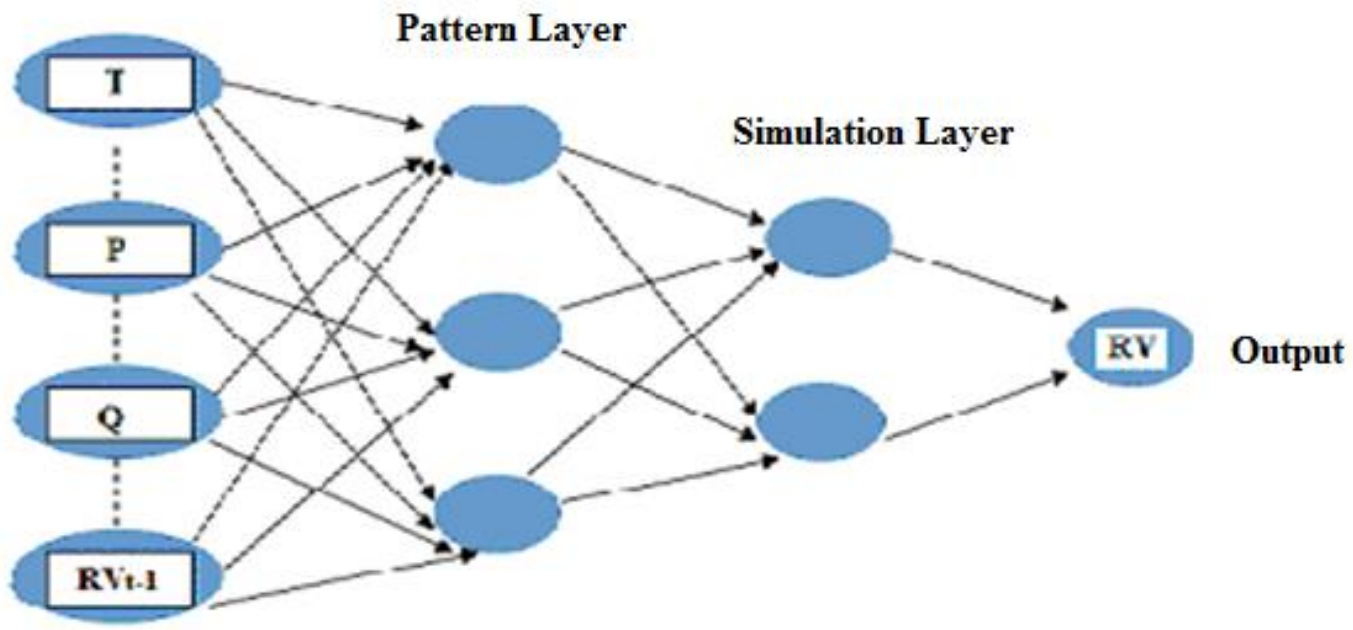

Figure 3. Structure of GRNN1 model used in this study

In GRNN1 model, Average temperature (T), Precipitation (P), Flow (Q), 1 lagged day reservoir volume (RVt-1) were taken as input and reservoir volume (RV) was predicted as output. 


\section{Results and discussion}

The results were used to compare the performance of the model estimation and the observation data. The comparison of RMSE, MAE and $\mathrm{R}^{2}$ parameters obtained from the test data is shown in Table 1.

Table 1. Performance comparison of models

\begin{tabular}{|c|c|c|c|c|}
\hline Methods & Method inputs & RMSE & MAE & $\mathbf{R}^{2}$ \\
\hline GRNN1 & $\mathrm{T}_{\mathrm{t}}, \mathrm{Q}_{\mathrm{t}}, \mathrm{P}_{\mathrm{t}}, \mathrm{RV}_{\mathrm{t}-1}$ & 41.5001 & 27.1486 & 0.8636 \\
\hline GRNN2 & $T_{t}, Q_{t}, P_{t}, P_{t-1}, R V_{t-1}$ & 37.1542 & 25.0508 & 0.8935 \\
\hline GRNN3 & $T_{t}, Q_{t}, Q_{t-1}, P_{t}, P_{t-1}, R V_{t-1}$ & 36.9193 & 24.7788 & $\underline{0.8951}$ \\
\hline M5T 1 & $\mathrm{~T}_{\mathrm{t}}, \mathrm{Q}_{\mathrm{t}}, \mathrm{P}_{\mathrm{t}}, \mathrm{RV}_{\mathrm{t}-1}$ & 25.0649 & 16.9725 & 0.9465 \\
\hline M5T 2 & $\mathrm{~T}_{\mathrm{t}}, \mathrm{Q}_{\mathrm{t}}, \mathrm{P}_{\mathrm{t}}, \mathrm{P}_{\mathrm{t}-1}, \mathrm{RV}_{\mathrm{t}-1}$ & 22.4109 & 14.9732 & 0.9577 \\
\hline M5T 3 & $T_{t}, Q_{t}, Q_{t-1}, P_{t}, P_{t-1}, R V_{t-1}$ & 22.1890 & 14.9199 & $\underline{0.9584}$ \\
\hline SVM RBF1 & $\mathrm{T}_{\mathrm{t}}, \mathrm{Q}_{\mathrm{t}}, \mathrm{P}_{\mathrm{t}}, \mathrm{RV}_{\mathrm{t}-1}$ & 24.0233 & 15.5659 & 0.9523 \\
\hline SVM RBF2 & $\mathrm{T}_{\mathrm{t}}, \mathrm{Q}_{\mathrm{t}}, \mathrm{P}_{\mathrm{t}}, \mathrm{P}_{\mathrm{t}-1}, \mathrm{RV}_{\mathrm{t}-1}$ & 22.2190 & 14.7506 & 0.9591 \\
\hline SVM RBF3 & $\mathbf{T}_{t}, \mathbf{Q}_{\mathrm{t}}, \mathbf{Q}_{\mathrm{t}-1}, \mathbf{P}_{\mathrm{t}}, \mathbf{P}_{\mathrm{t}-1}, \mathbf{R} \mathbf{V}_{\mathrm{t}-1}$ & 21.8718 & 14.4796 & $\underline{0.9605}$ \\
\hline SVM PK1 & $\mathrm{T}_{\mathrm{t}}, \mathrm{Q}_{\mathrm{t}}, \mathrm{P}_{\mathrm{t}}, \mathrm{RV}_{\mathrm{t}-1}$ & 23.9572 & 15.2520 & 0.9536 \\
\hline SVM PK2 & $\mathrm{T}_{\mathrm{t}}, \mathrm{Q}_{\mathrm{t}}, \mathrm{P}_{\mathrm{t}}, \mathrm{P}_{\mathrm{t}-1}, \mathrm{RV}_{\mathrm{t}-1}$ & 22.1670 & 14.4932 & 0.9605 \\
\hline SVM PK3 & $T_{t}, Q_{t}, Q_{t-1}, P_{t}, P_{t-1}, R V_{t-1}$ & 21.8393 & 14.2555 & $\underline{0.9617}$ \\
\hline
\end{tabular}

RMSE: root mean square error, MAE: mean absolute error, $\mathrm{R}^{2}$ : determination coefficient

In this study, Mean Air Temperature $\left(T_{t}\right)$, Flow $\left(Q_{t}\right)$, the lagged time Flow $\left(Q_{t-1}\right)$, Mean Precipitation $\left(\mathrm{P}_{\mathrm{t}}\right)$, the lagged time Precipitation $\left(\mathrm{P}_{\mathrm{t}-1}\right)$ and the lagged time Reservoir Storage $\left(\mathrm{RV}_{\mathrm{t}-1}\right)$ were used to reservoir storage capacity prediction.

The temperature, precipitation, flow and lagged time reservoir volume of the Stony Brook dam were taken as input. 2126 of 3726 data were used for the training; remaining 1600 data were applied for the test. The results obtained by the model were compared with the measured values. Obtained results of these studies are given in Table 1.

Predictions were made by using Generalized Neural Network (GRNN), Support Vector Machines with basic radial functions (SVM-RBF), Support Vector Machines with poly kernel (SVM-PK) and Decision Tree Methods (M5T). Three evaluations were made in all three models. Estimation results of the models were compared according to $\mathrm{R}^{2}$ (Determination Factor), Mean Absolute Error (MAE) and Root Mean Square Error (RMSE) criteria.

In GRNN1, SVM RBF1, SVM PK1 and M5T 1 models, average temperature (T), Precipitation $(\mathrm{P})$, Flow $(\mathrm{Q}), 1$ lagged day reservoir volume $\left(\mathrm{RV}_{\mathrm{t}-1}\right)$ were taken as input, In GRNN2, SVM RBF2, SVM PK2 and M5T 2 models, average temperature (T), Precipitation $(\mathrm{P})$, Flow $(\mathrm{Q}), 1$ lagged day Precipitation $\left(\mathrm{P}_{\mathrm{t}-1}\right)$ and1 lagged day reservoir volume $\left(\mathrm{V}_{\mathrm{t}-1}\right)$ were taken as input In GRNN3, SVM RBF3, SVM PK3 and M5T 3 models, average temperature $(\mathrm{T})$, Precipitation $(\mathrm{P})$, Flow $(\mathrm{Q})$, 1 lagged day Flow $\left(\mathrm{Q}_{\mathrm{t}-1}\right)$, 1 lagged day Precipitation $\left(\mathrm{P}_{\mathrm{t}-1}\right)$ and 1 lagged day reservoir volume $\left(\mathrm{V}_{\mathrm{t}-1}\right)$ were taken as input.

Scatter and distribution graphs showing the relationships of the three models with the real data are shown in Figure 4 for GRNN, Figure 5 for M5T, Figure 6 for SVM PK and Figure 7 for SVM RBF. 


$$
-7050 \text { - }
$$
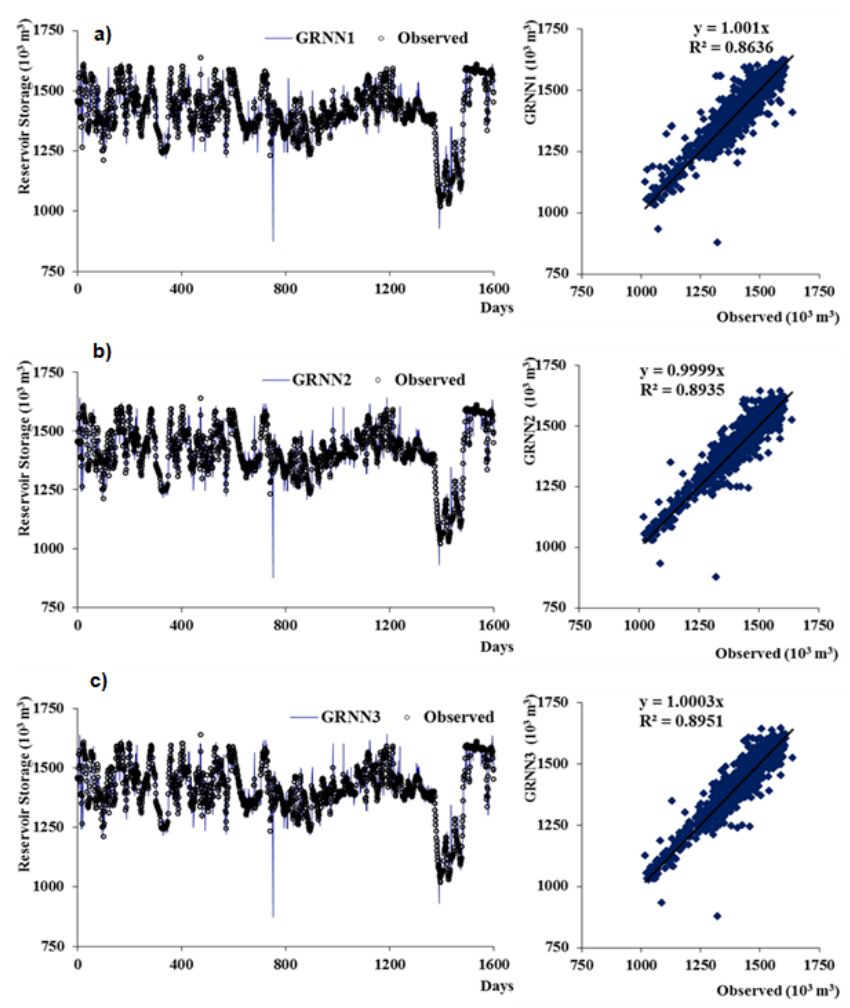

Figure 4. Observed and GRNN distribution-scatter chart for dam reservoir volume test data a GRNN1, b GRNN2, c GRNN3
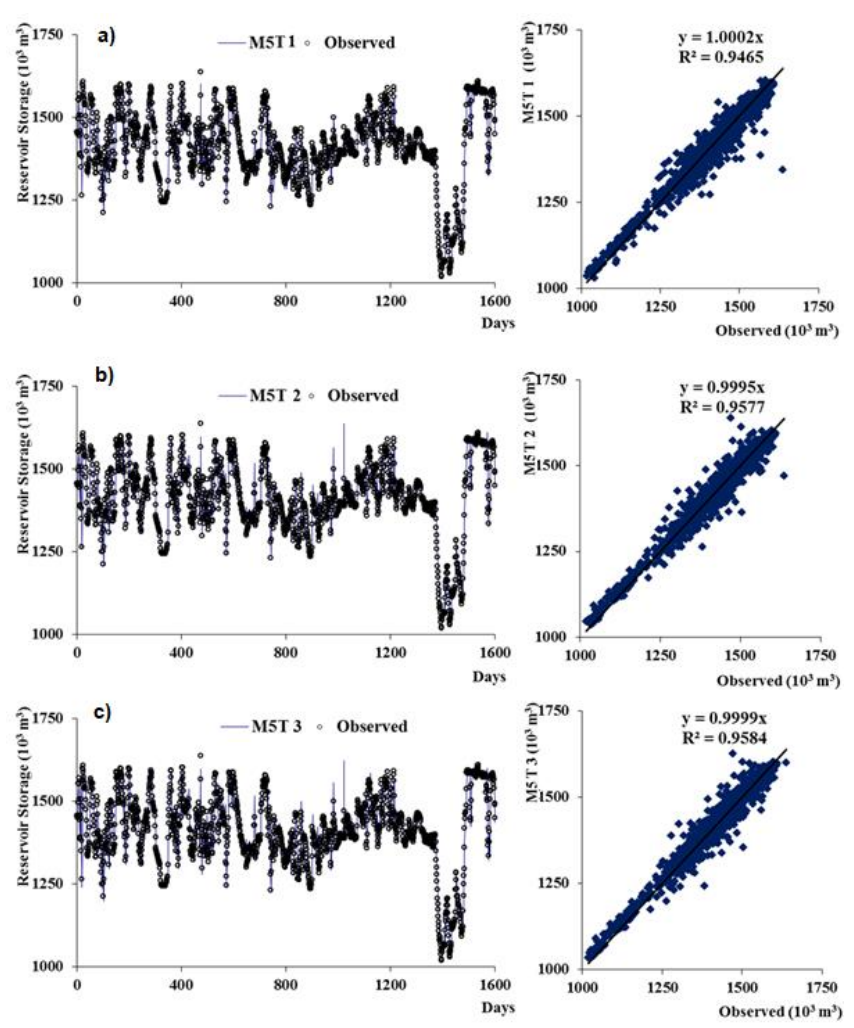

Figure 5. Observed and M5T distribution-scatter chart for dam reservoir volume test data a M5T 1, b M5T 2, c M5T 3 


$$
-7051-
$$
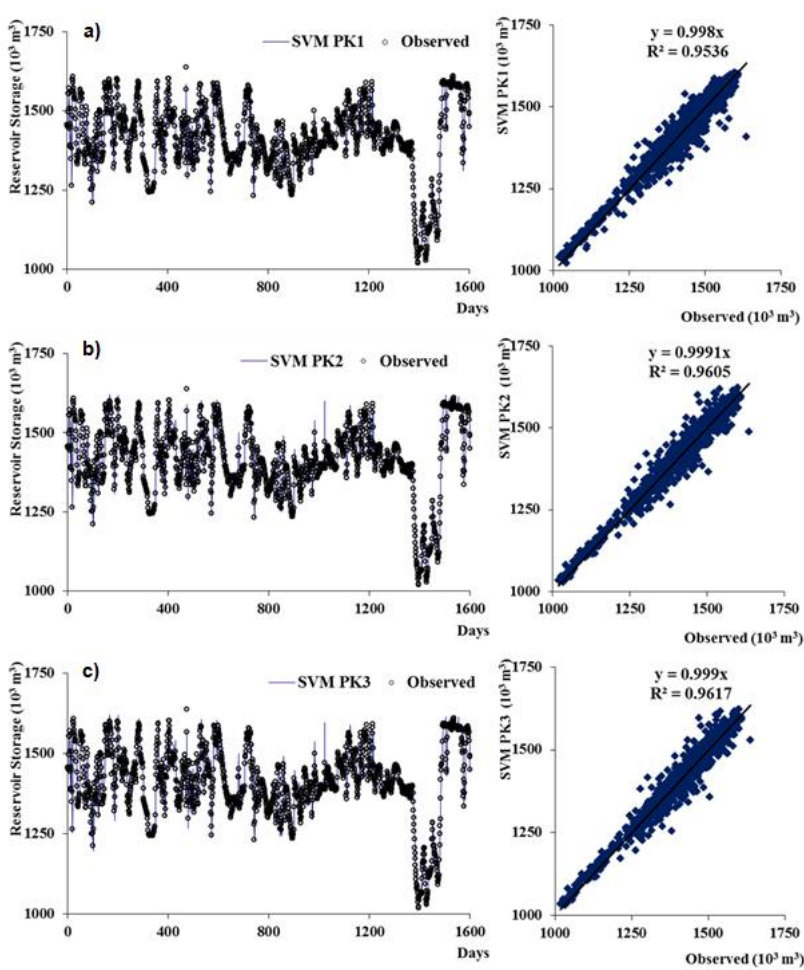

Figure 6. Observed and SVM-PK distribution-scatter chart for dam reservoir volume test data a $S V M P K 1, \boldsymbol{b} S V M P K 2, \boldsymbol{c} S V M P K 3$
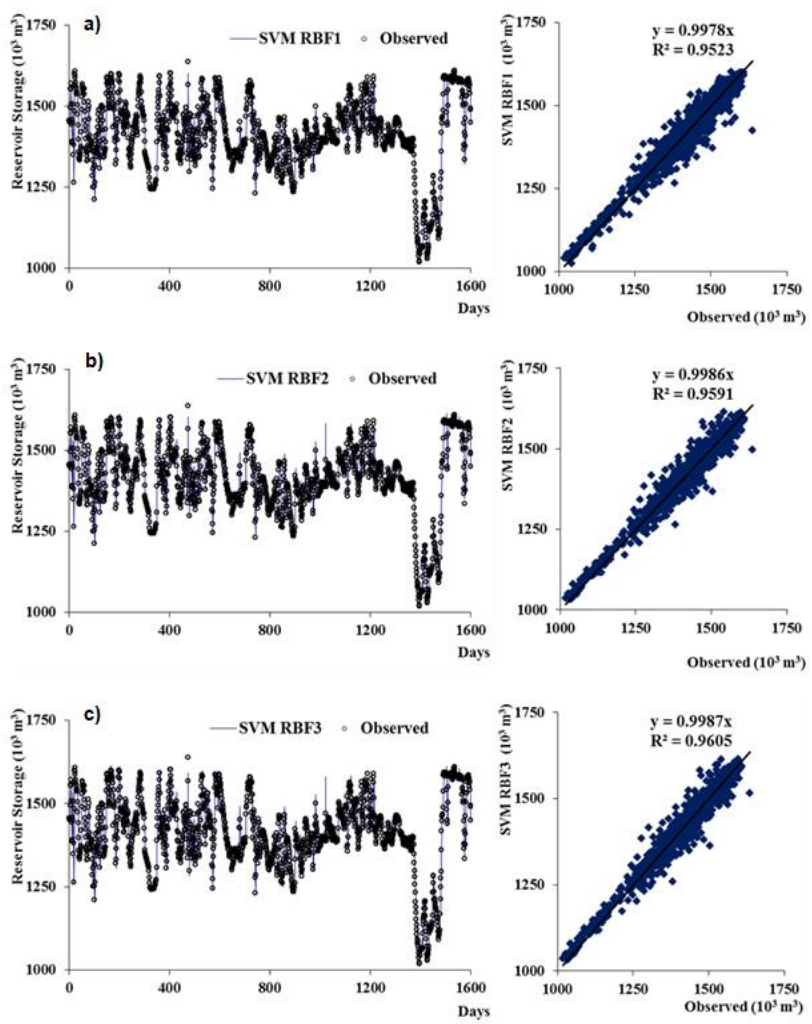

Figure 7. Observed and SVM-PK distribution-scatter chart for dam reservoir volume test data a $S V M R B F 1, \boldsymbol{b} S V M R B F 2, \boldsymbol{c} S V M R B F 3$ 
The performance of GRNN model is presented graphically in Figure 4. If the distribution and scatter graphs are examined, there is a good relationship between the estimated and observed values. When we looked at the RMSE, MAE and $\mathrm{R}^{2}(21.8718$, 14.4796, 0.9605) shown in Table 1, compared to other models, GRNN models showed the worst performance.

Data for 3726 days were evaluated for M5T models and the results were defined as follows. The distribution and scatter graphs of the M5T models are shown in Figure 5. When the distribution and scatter patterns are examined, the estimated values are close to the actual values. When we look at the benchmark values of RMSE, MAE and $\mathrm{R}^{2}$ (22.1890, 14.9199, 0.9584) shown in Table 1, the M5T 3 model result are better than the other M5T models. Generally M5T model results showed better performance than GRNN models but showed better a little bit worst performance compared with SVM models.

In Figure 6, when the SVM RBF models are considered, it is seen that the determination coefficient is high and dam reservoir volume estimations are close to the actual values. The SVM RBF3 model showed low error, high correlation and better performance than other SVM RBF models according to the criteria of RMSE, MAE and $\mathrm{R}^{2}(21.8718,14.4796,0.9605)$ as shown in Table 1.

For SVM PK models, the distribution and scatter plots are shown in Figure 7. When the scatter graphs were analyzed for the test data, SVM PK model results showed a better performance than SVM RBF models. The SVM PK3 model estimates are close to the actual values. In the SVM PK3 model with the highest coefficient of determination, $\mathrm{R}^{2}=0.9617$. The SVM PK3 model gave best results than the other SVM PK, SVM RBF, GRNN and M5T models according to the criteria of RMSE, MAE and $\mathrm{R}^{2}$ $(21.8393,14.2555,0.9617)$

\section{Conclusion}

In this study, Stony Brook dam reservoir volumes estimated by using Support Vector Machines with Radial Base Functions (SVM-RBF), Support Vector Machines with Poly Kernel (SVM-PK), Generalized Regression Neural Network (GRNN) and M5 Decision Tree (M5T). Precipitation, temperature, discharge parameters were applied as input to the models. The results were compared to the actual results and the relationship between the models was examined. As a result of the study in this paper it is possible to derive the following conclusions.

Different combinations of inputs parameters were used for each model. As it is expected, the model which use the all four suggested parameters as input has better performance than the other combinations in SVM, GRNN and M5T models.

Comparing all models, SVM-PK models have better performance in predicting dam reservoir volume. The SVM PK-3 model provides the best performance according to the low amount of error (RMSE, MAE) ratios and high coefficient of determination $\left(\mathrm{R}^{2}\right)$. In all models, GRNN models showed the worst performance in the prediction reservoir dam volume. SVM model performances are preferably better than M5T models. It is possible to state that However, comparisons indicate that Support Vector Machines model solutions can provide a tighter fit to the observed data. It was seen that SVM-PK method had less error than the SVM-RBF method.

The ANN correctly adapts to the changing input conditions, such as irrigation policy changes in this example. This is quite important since similar sudden changes can be 
observed on the related time series within the reservoir operation management studies. The advantages of applied soft computing techniques in this study over past conventional methods in the prediction of reservoir volume can be explained by saying that soft computing techniques structure includes the non-linear dynamics of the problem in the whole data set.

The monthly reservoir volume estimations obtained results based on this study can be quite informative for the determination of flood planning and management, the hydroelectric energy computations, design and operation of the hydraulic structures, navigation in the dam reservoirs, water supply for municipalities and industries, irrigation and drainage, flood damage reduction and water quantity modeling in the reservoir.

Acknowledgements. The data used in this study were downloaded from the web server of the USGS. The authors wishes to thank the staff of the USGS who are associated with data observation, processing, and management of USGS websites.

\section{REFERENCES}

[1] Antonanzas, J., Urraca, R., Martinez-de-Pison, F. J., Antonanzas-Torres, F. (2015): Solar irradiation mapping with exogenous data from support vector regression machines estimations. - Energy Conversion and Management 100: 380-390.

[2] Asefa, T., Kemblowski, M., Lall, U., Urroz, G. (2005): Support vector machines for nonlinear state space reconstruction: application to the Great Salt Lake time series. Water Resources Research 41(12). DOI: 10.1029/2004WR003785.

[3] Bhattacharya, B., Solomatine, D. P. (2005): Neural networks and M5 model trees in modelling water level-discharge relationship. - Neurocomputing 63: 381-396.

[4] Bray, M., Han, D. (2004): Identification of support vector machines for runoff modelling. - Journal of Hydroinformatics 6(4): 265-280.

[5] Chitsaz, N., Azarnivand, A., Araghinejad, S. (2016): Pre-processing of data-driven river flow forecasting models by singular value decomposition (SVD) technique. - Hydrol Sci J 61(12): 2164-2178.

[6] Chen, H., Guo, J., Xiong, W., Guo, S., Xu, C. Y. (2010): Downscaling GCMs using the Smooth Support Vector Machine method to predict daily precipitation in the Hanjiang Basin. - Advances in Atmospheric Sciences 27(2): 274-284.

[7] Cortes, C., Vapnik, V. (1995): Machine learning. - Support Vector Networks 20: 273297.

[8] Demirci, M., Baltaci, A. (2013): Prediction of suspended sediment in river using fuzzy logic and multilinear regression approaches. - Neural Computing and Applications 23(1): $145-151$.

[9] Demirci, M., Unes, F., Saydemir, S. (2015a): Suspended Sediment Estimation Using an Artificial Intelligence Approach. - In: Heininger, P., Cullmann, P. (eds.) Sediment Matters. Springer, Switzerland, pp. 83-95.

[10] Demirci, M., Unes, F., Aköz, M. S. (2015b): Prediction of cross-shore sandbar volumes using neural network approach. - Journal of Marine Science and Technology 20(1): 171179.

[11] Demirci, M., Unes, F., Kaya, Y. Z., Tasar, B., Varcin, H. (2018): Modeling of dam reservoir volume using adaptive neuro fuzzy method. - Conference Aerul si Apa. Componente ale Mediului, pp. 145-152. DOI: 10.24193/AWC2018_18.

[12] Demirci, M., Unes, F., Körlü, S. (2019): Monthly groundwater level modeling of Reyhanli region in Turkey using artificial intelligence techniques. - Applied Ecology and 
Environmental Research 17(2):

2651-2663.

DOI:

http://dx.doi.org/10.15666/aeer/1702_26512663.

[13] Dibike, Y. B., Velickov, S., Solomatine, D., Abbott, M. B. (2001): Model induction with support vector machines: introduction and applications. - Journal of Computing in Civil Engineering 15(3): 208-216.

[14] Ergezer, H., Dikmen, M., Özdemir, E. (2003): Yapay sinir ağları ve tanıma sistemleri. PiVOLKA 2(6): 14-17.

[15] Esmaeilzadeh, B., Sattari, M. T., Samadianfard, S. (2017): Performance evaluation of ANNs and an M5 model tree in Sattarkhan Reservoir inflow prediction. - ISH Journal of Hydraulic Engineering 23(3): 283-292.

[16] Fernando, D. A. K., Jayawardena, A. W. (1998): Runoff forecasting using RBF networks with OLS algorithm. - Journal of Hydrologic Engineering 3(3): 203-209.

[17] Goyal, M. K., Ojha, C. S. P., Singh, R. D., Swamee, P. K., Nema, R. K. (2013): Application of ANN, fuzzy logic and decision tree algorithms for the development of reservoir operating rules. - Water Resources Management 27(3): 911-925.

[18] Hosseini, S. M., Mahjouri, N. (2016): Integrating support vector regression and a geomorphologic artificial neural network for daily rainfall-runoff modeling. - Applied Soft Computing 38: 329-345.

[19] Hsu, C. W., Chang, C. C. Lin, C. J. (2003): A Practical Guide to Support Vector Classification. - Tech. Report, Dept Computer Sci. \& Info. Engng, National Taiwan University, Taiwan, China.

[20] Kaya, Y. Z., Üneş, F., Demirci, M., Taşar, B., Varçin, H. (2018): Groundwater level prediction using artificial neural network and M5 tree models. - Conference Aerul si Apa. Componente ale Mediului, pp. 195-201. DOI: 10.24193/AWC2018_23.

[21] Khalil, A. F., McKee, M., Kemblowski, M., Asefa, T., Bastidas, L. (2006): Multiobjective analysis of chaotic dynamic systems with sparse learning machines. Advances in Water Resources 29(1): 72-88.

[22] Khan, M. S., Coulibaly, P. (2006): Application of support vector machine in lake water level prediction. - Journal of Hydrologic Engineering 11(3): 199-205.

[23] Mason, J. C., Price, R. K., Tem'Me, A. (1996): A neural network model of rainfall-runoff using radial basis functions. - Journal of Hydraulic Research 34(4): 537-548.

[24] McCulloch, W. S., Pitts, W. (1943): A logical calculus of the ideas immanent in nervous activity. - The Bulletin of Mathematical Biophysics 5(4): 115-133.

[25] Minns, A. W., Hall, M. J. (1996): Artificial neural networks as rainfall-runoff models. Hydrological Sciences Journal 41(3): 399-417.

[26] Nieto, P. G., Torres, J. M., Fernández, M. A., Galán, C. O. (2012): Support vector machines and neural networks used to evaluate paper manufactured using Eucalyptus globulus. - Applied Mathematical Modelling 36(12): 6137-6145.

[27] Quinlan, J. R. (1992): Learning with continuous classes. - 5th Australian Joint Conference on Artificial Intelligence 92: 343-348.

[28] Radhika, Y., Shashi, M. (2009): Atmospheric temperature prediction using support vector machines. - International Journal of Computer Theory and Engineering 1(1): 55.

[29] Rao, M., Fan, G., Thomas, J., Cherian, G., Chudiwale, V., Awawdeh, M. (2007): A webbased GIS decision support system for managing and planning USDA's conservation reserve program (CRP). - Environmental Modelling \& Software 22(9): 1270-1280.

[30] Sattari, M. T., Pal, M., Apaydin, H., Ozturk, F. (2013): M5 model tree application in daily river flow forecasting in Sohu Stream, Turkey. - Water Resources 40(3): 233-242.

[31] Solomatine, D. P., Xue, Y. (2004): M5 model trees and neural networks: application to flood forecasting in the upper reach of the Huai River in China. - Journal of Hydrologic Engineering 9(6): 491-501.

[32] Specht, D. F. (1991): A general regression neural network. - IEEE Transactions on Neural Networks 2(6): 568-576. 
[33] Tasar, B., Kaya, Y. Z., Varçin, H., Unes, F., Demirci, M. (2017): Forecasting of suspended sediment in rivers using artificial neural networks approach. - International Journal of Advanced Engineering Research and Science 4(12): 79-84.

[34] Tasar, B., Unes, F., Demirci, M., Kaya, Y. Z. (2018): Yapay sinir ağları yöntemi kullanılarak buharlaşma miktarı tahmini. - DÜMF Mühendislik Dergisi 9(1): 543-551.

[35] Turhan, E. (2012): Seyhan Havzası'nın Yağış. - Akış İlişkisinin Yapay Sinir Ağları Yöntemi ile Modellenmesi, Yüksek Lisans Tezi, Adana.

[36] Unes, F. (2010a), Dam reservoir level modeling by neural network approach: a case study. - Neural Network World 4(10): 461.

[37] Unes, F. (2010b): Prediction of density flow plunging depth in dam reservoirs: an artificial neural network approach. - Clean-Soil, Air, Water 38(3): 296-308.

[38] Unes, F., Yildirim, S., Cigizoglu, H. K., Coskun, H. (2013): Estimation of dam reservoir volume fluctuations using artificial neural network and support vector regression. Journal of Engineering Research 1(3): 53-74.

[39] Unes, F., Gumuscan, F. G., Demirci, M. (2017): Prediction of dam reservoir volume fluctuations using adaptive neuro fuzzy approach. - EJENS 2(1): 144-148.

[40] USGS.gov | Science for a changing world. - https://www.usgs.gov/.

[41] Vapnik, V. (1995): The Nature of Statistical Learning Theory. - Springer, New York.

[42] Vapnik, V., Golowich, S., Smola, A. (1997): Support Vector Method for Function Approximation, Regression Estimation, and Signal Processing. - In: Jordan, M. I. et al. (eds.) Advances in Neural Information Processing Systems. MIT Press, Cambridge, MA, pp. 281-287.

[43] Witten, I. H., Frank, E. (2005): Data Mining: Practical Machine Learning Tools and Techniques with Java Implementations. - Morgan Kaufmann, San Francisco, CA.

[44] Yin S, Tang D, Jin X, Chen W, Pu N (2016): A combined rotated general regression neural network method for river flow forecasting. - Hydrol Sci J 61(4): 669-682.

[45] Yu, P. S., Chen, S. T., Chang, I. F. (2006): Support vector regression for real-time flood stage forecasting. - Journal of Hydrology 328(3-4): 704-716. 